\title{
Rare cause of lower gastrointestinal bleed
}

\author{
Mukesh Nasa, Mahesh Gupta, Randhir Sud, Lipika Lipi ${ }^{1}$ \\ Institute of Digestive and Hepatobiliary Sciences, 'Department of Pathology, Medanta-The Medicity, \\ Gurgaon, Haryana, India
}

\begin{abstract}
Gastrointestinal (GI) mucormycosis commonly affects adults with neutropenia or other immunocompromising conditions. Gl mucormycosis is uncommon but has high mortality rate. We report a case of colonic mucormycosis in a patient of chronic obstructive airway disease who presented with massive lower GI bleed.

Key words Adenomatous polyposis coli, colonic mucormycosis, lower gastrointestinal bleed
\end{abstract}

\section{Introduction}

Mucormycosis is caused by environmental fungi of the class Zygomycetes, subphylum Mucoromycotina and order Mucorales and mainly by species of genera Rhizopus. ${ }^{[1]}$ It mostly affects patients with uncontrolled diabetes, defects in phagocytes and organ or hematopoietic stem cell transplantation ${ }^{[2,3]}$ Gastrointestinal mucormycosis is an uncommon entity associated with high mortality. Diagnosis is established by biopsy. Within the gastrointestinal tract, stomach is the most common site of involvement followed by that of colon. ${ }^{[4]}$

\section{Case Report}

Gastrointestinal (GI) mucormycosis is uncommon but has high mortality despite aggressive treatment.

A 65-year-old male patient, with chronic obstructive airway disease on inhalation steroid treatment, nondiabetic, nonhypertensive, presented with the complaints of 8-10 episode of painless fresh bleeding per rectum. On admission, the general condition of the patient was poor with systolic blood pressure of $70 \mathrm{~mm}$ of $\mathrm{Hg}$. His systemic, examination was normal except per rectum examination, that showed rectum

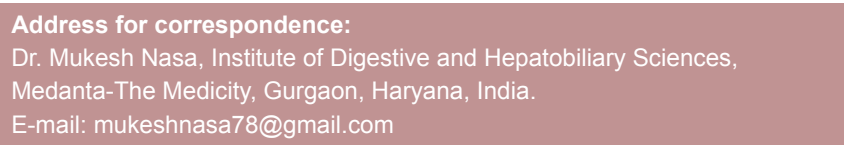

\begin{tabular}{|l|c|}
\hline \multicolumn{2}{|c|}{ Access this article online } \\
\hline \multirow{2}{*}{$\begin{array}{l}\text { Website: } \\
\text { www.jdeonline.in }\end{array}$} & Quick Response Code \\
\hline DOI: & \\
10.4103/0976-5042.202811 & \\
\hline
\end{tabular}

full with blood clots. Laboratory examination revealed his $\mathrm{Hb}-9.1$, total lymphocyte count of $2380 / \mathrm{mm}^{3}$, platelet count 1.50 lakhs $/ \mathrm{mm}^{3}$, peripheral smear showed mild lymphocytosis, serum creatinine- $2.9 \mathrm{mg} / \mathrm{dl}, \mathrm{Na}-137 \mathrm{mEq} / \mathrm{L}, \mathrm{K}-2.8 \mathrm{mEq} / \mathrm{L}$, serum bilirubin- $0.8 \mathrm{mg} / \mathrm{dl}$, serum AST $132 \mathrm{IU} / \mathrm{L}$, ALT $99 \mathrm{IU} / \mathrm{L}$ and INR 1.14, random blood sugar-130. He was started on intravenous antibiotics, fluid, and other supportive measures. His ultrasonography abdomen was done suggestive of fatty liver with cholethiasis. His upper GI endoscopy was normal, colonoscopy showed circumferential deep ulcers in cecum, ascending, and sigmoid colon with active oozing that was controlled with argon plasma coagulation [Figure 1]. Multiple biopsies were taken from the colonic ulcers to ascertain the etiology. Histopathology of ulcer biopsy was suggestive of angioinvasive mucormycosis [Figures 2 and 3 ] so he was started on amphotericin-B and posaconazole. Despite ongoing antifungal and antibiotic treatment, the patient had worsening clinical course. Later on, he required ventilator support and multiple dialyses and finally he succumbed.

\section{Discussion}

Mucormycosis mostly affects patients with uncontrolled diabetes, defects in phagocytosis and organ or hematopoietic stem cell transplantation. ${ }^{[2,3]}$ Incidence of mucormycosis has also increased because of frequent use of antibiotics and steroids.

This is an open access article distributed under the terms of the Creative Commons Attribution-NonCommercial-ShareAlike 3.0 License, which allows others to remix, tweak, and build upon the work non-commercially, as long as the author is credited and the new creations are licensed under the identical terms.

For reprints contact: reprints@medknow.com

How to cite this article: Nasa M, Gupta M, Sud R, Lipi L. Rare cause of lower gastrointestinal bleed. J Dig Endosc 2017;8:27-8. 


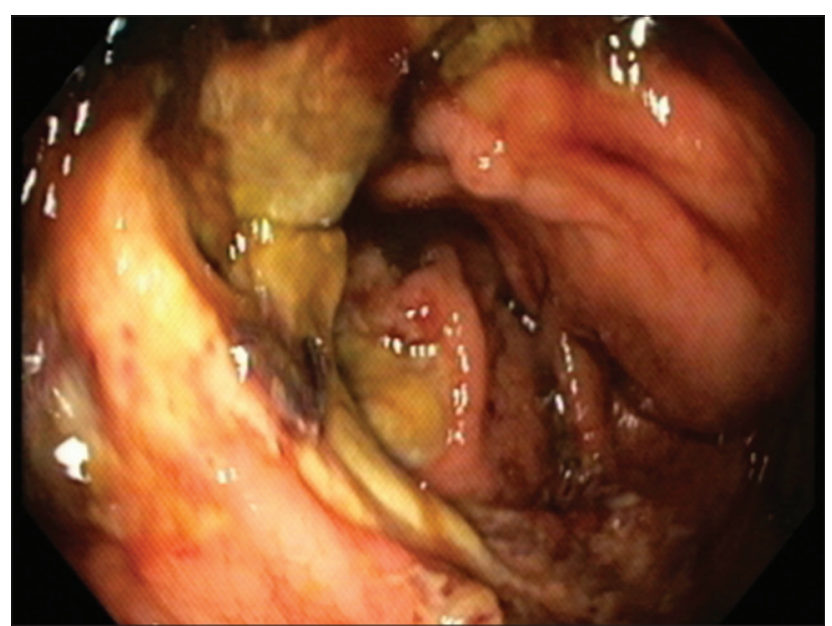

Figure 1: Colonoscopic image showing large ulcer in sigmoid colon

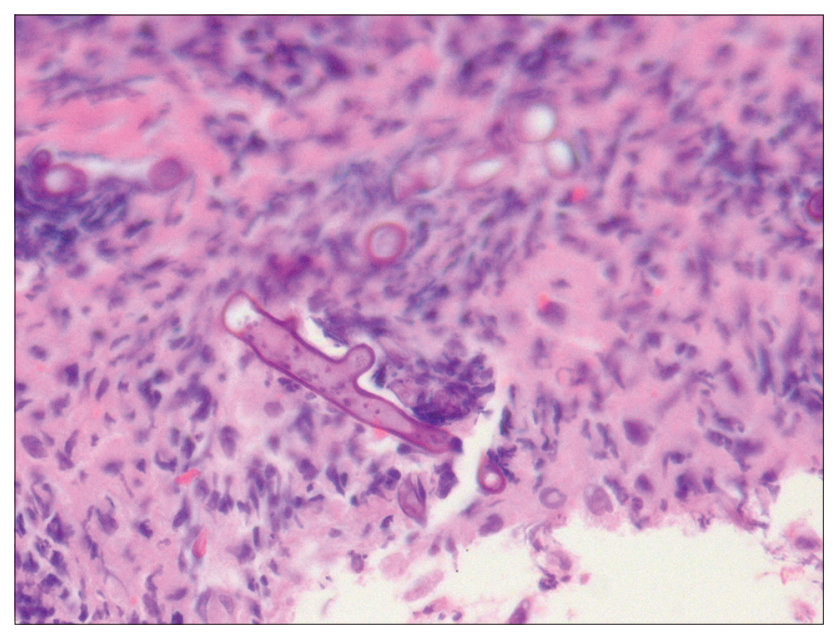

Figure 2: Microscopic image of colonic biopsy showing aseptate hyphae invading vessel suggestive of mucormycosis

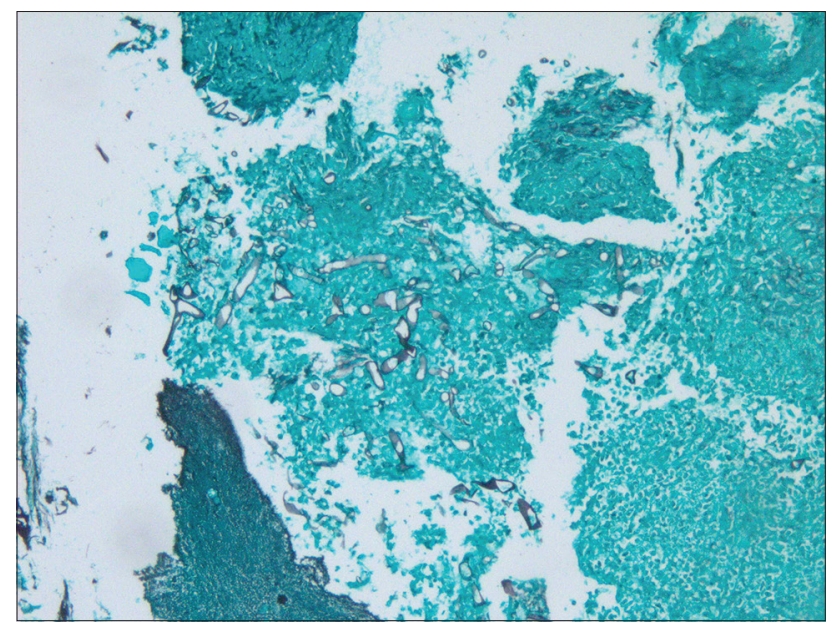

Figure 3: Microscopic image of colonic biopsy on Gomori methenamine silver stain showing mucormycosis

Histopathological examination remains the most sensitive and specific modality for definitive diagnosis. Biopsy reveals characteristic wide $(6-30 \mu)$, thick-walled, ribbon-like, aseptate hyphae that branch at the right angles.
Based on the involvement of a particular anatomic site mucormycosis is divided into five categories (1) rhinocerebral, (2) pulmonary, (3) cutaneous, (4) GI, and (5) disseminated. Gastrointestinal mucormycosis comprise 7\% of the reported cases. ${ }^{[5]}$ Invasive GI mucormycosis has a mortality rate of over $90 \%{ }^{[6]}$ whereas in disseminated disease, it can be as high as $100 \%{ }^{[3]}$

Diagnosis of mucormycosis can be based on either growth of the mold on culture or histopathologic demonstration on biopsy of aseptate, wide, ribbon-like hyphae that branch at the right angles. ${ }^{[3,7]}$ However, due to the difficulty of growing organisms from tissue culture, biopsy with histologic identification remains the preferred mode of diagnosis. ${ }^{[7]}$

Treatment for mucormycosis consists of both surgical debridements of necrotic material and administration of liposomal or lipid-based formulations of amphotericin-B. ${ }^{[3]}$ Depending on the site of infection, surgical debridement may not be possible or plausible as in cases of disseminated disease. Adjunctive treatment options such as the use of nonsiderophore iron chelators, hyperbaric oxygen, or cytokine therapy with either gamma interferon or colony-stimulating factor are being investigated, but these methods have not yet proven to be more beneficial than standard treatment with surgery and amphotericin B. ${ }^{[8,9]}$

\section{Financial support and sponsorship}

Nil.

\section{Conflicts of interest}

There are no conflicts of interest.

\section{References}

1. Ananthnarayan R, Jayaram CK. PanikerTextbook of Microbiology. $6^{\text {th }}$ ed. Chennai: Orient Longman Ltd; 2000. p. 564-80.

2. Marr KA, Carter RA, Crippa F, Wald A, Corey L. Epidemiology and outcome of mould infections in hematopoietic stem cell transplant recipients. Clin Infect Dis 2002;34:909-17.

3. Spellberg B, Edwards J Jr., Ibrahim A. Novel perspectives on mucormycosis: Pathophysiology, presentation, and management. Clin Microbiol Rev 2005;18:556-69.

4. Han JY, Cheon JH, Kim DH, Chon HJ, Kim SK, Kim TI, et al. Ileal mucormycosis diagnosed by colonoscopy in a patient with acute myeloid leukemia. Korean J Gastroenterol 2008;52:179-82.

5. Roden MM, Zaoutis TE, Buchanan WL, Knudsen TA, Sarkisova TA, Schaufele RL, et al. Epidemiology and outcome of zygomycosis: A review of 929 reported cases. Clin Infect Dis 2005;41:634-53.

6. Tinmouth J, Baker J, Gardiner G. Gastrointestinal mucormycosis in a renal transplant patient. Can J Gastroenterol 2001;15:269-71.

7. Kauffman CA, Malani AN. Zygomycosis: An emerging fungal infection with new options for management. Curr Infect Dis Rep 2007;9:435-40.

8. Agha FP, Lee HH, Boland CR, Bradley SF. Mucormycoma of the colon: Early diagnosis and successful management. AJR Am J Roentgenol 1985;145:739-41.

9. Boelaert JR, Van Cutsem J, de Locht M, Schneider YJ, Crichton RR. Deferoxamine augments growth and pathogenicity of Rhizopus, while hydroxypyridinone chelators have no effect. Kidney Int 1994;45:667-71.

Jaurnal of Digestive Endoscopy 